\title{
Concept-based Curriculum Development, Implementation, and Evaluation: A Systematic Review
}

\section{Susan K. Lee ${ }^{1, *}$ and Pamela Willson ${ }^{2}$}

${ }^{1}$ Nursing Consultant, Austin, TX 78731, USA

${ }^{2}$ Clinical Professor, School of Nursing, Texas State University, San Marcos, TX 78666, USA

\begin{abstract}
Background: Concept-based curriculum (CBC) is a teaching method that enhances learning by eliminating information overload and memorization; allowing students to think critically by linking knowledge gained in the didactic setting or from previous experiences to apply to clinical practice. $\mathrm{CBC}$ is currently implemented in some nursing education programs across the United States. The content-laden curriculum found in traditional nursing education programs, often grounded in the systems approach, has created an environment where faculty are challenged to address current practice competency content while students struggle to gain and retain information. Often students resort to memorization of nursing knowledge and skills rather than understand scientific processes or evidence-based rationale.
\end{abstract}

Methods: A systematic search of the literature was conducted to determine the state of the science of concept-based curriculum's implementation in nursing education. Academic Search Complete, ProQuest Nursing, CINAHL, and PubMed databases were searched using nursing, education, concept(s), conceptbased, and nursing education as search terms. Inclusion criteria was limited to English, peer-reviewed academic and research publications for the years 1990-2017.

Results: Sixty-four reports were retrieved, 32 met eligibility and are included in the qualitative synthesis of the strengths, weaknesses, opportunities, and threats (SWOT) to CBC. The SWOT analysis is reported by $\mathrm{CBC}$ development, implementation into the curriculum, and evaluation of the implementation.

Conclusion: Programmatic implementation strategies are described and outcome metrics are identified that may serve as benchmarks for programs and regulators. Concept-based curricular approaches were found to promote higher levels of thinking, such as evaluating, analyzing, and processing; and to improve critical thinking and clinical judgment as students apply new knowledge within the frame of the concept and analyze information.

\section{Concept-based Curricula Background}

Traditionally, nursing education programs have focused on the assumption that knowing facts is evidence of understanding where the learner is passive, relying on memorization and fragmented factual knowledge. The traditional curriculum design encourages shallow teaching and learning rather than promoting clinical decision making. Bloom's Taxonomy [1], which is a basis of traditional nursing education, is limited in enabling students to process data at deeper levels, retain knowledge, or transfer information between situations [2-4]. The inability of nursing students to successfully develop a plan of care for a client they never met was evident as the curriculum focused on medical diagnoses and lab results [5]

Nurses practice conceptually by focusing on the patient regardless of the medical diagnosis, grouping information between patients. However, content-laden curriculum in traditional nursing education programs has created an environment where faculty struggle to teach all of the content $[4,6]$. Changes in technology and nursing shortages, along with a shift to population and global health, chronic disease management, and health promotion motivated educators to reexamine nurse education curricula. Curriculum reform and a complete paradigm shift in nursing education have been suggested to connect innovative undergraduate nursing curriculum to clinical learning experiences [7]. To implement any type of curricular changes, faculty must be willing to adopt new methods of teaching, while fostering active learning and critical thinking skills [8-9].

Concept-based curricula enable synthesis and transferability of nursing knowledge across multiple situations as the concepts present logical solutions [10]. Hardin and Richardson [10] define concepts as social, cultural, and historical constructs that maintain form, structure, and patterns over time, while varying levels of abstraction from general to specific, focusing on how meaning is produced and used. Students begin with a personal understanding of a concept, that when applied to multiple contexts and situations, improves and expands beyond an isolated encounter. By applying concepts, data is linked to a situation, so that impressions, rather than facts, form the basis of understanding. Active learning techniques that incorporate sharing others' experiences actually facilitate students' grasp of the utility of concepts [10]. Students must be encouraged to become familiar with concepts and link them together, changing preconceptions when applied to new understandings. The instructional goal is for students to focus on connecting and identifying connections between concepts [11]. Faculty facilitate this process by correcting misconceptions and providing direction to link concepts [12]. When students understand concepts, knowledge is retained and transferred across situations. Unexpected events cause students to reassess situations and expected results, improving observation, assessment,

"Corresponding Author: Dr. Susan K. Lee, Nursing Consultant for Education, Texas Board of Nursing, Austin, TX 78701, USA, Tel: (512) 463-4631; E-mail: susan.lee@bon.texas.gov

Citation: Lee SK, Willson P (2018) Concept-based Curriculum Development Implementation, and Evaluation: A Systematic Review. Int J Nurs Clin Pract 5: 271. doi: https://doi.org/10.15344/2394-4978/2018/271

Copyright: ( 2018 Lee et al. This is an open-access article distributed under the terms of the Creative Commons Attribution License, which permits unrestricted use, distribution, and reproduction in any medium, provided the original author and source are credited. 
and evaluation skills to anticipate possible results and link concepts from old to new situations. Students must be encouraged to focus their attention on key elements in a simulation and then explain what happened. This causes students to question understanding of the concept, leading to an evolved understanding of the event [13].

In $\mathrm{CBC}$, the focus is on the definition, attributes, and patterns of concepts, and the role of the nurse in patient care. Students matriculate this information as concepts are applied in the form of exemplars, which are examples of ideas or notions that students rely on when information is presented to clarify concepts and connect learning to real-life situations. When these connections are formed, learning is retained, becoming retrievable and broadly applicable. Exemplars are an excellent means of presenting course content, and, thus, creating a wide-ranging, cohesive grouping of information, which can be applied to a variety of scenarios [14]. An advantage with traditional clinical learning environments is that students work with patients and nurses while applying knowledge to practice. A disadvantage is the students are too involved with client care, focusing on tasks rather than nursing care. Advantages of $\mathrm{CBC}$ in the clinical setting are that students learn about the patient and are able to connect nursing practice to safe patient care. Clinical experience should encourage student creativity and involvement, such as asking questions and debating principles to foster creative learning [15].

For example, $\mathrm{CBC}$ is currently implemented in some nursing education programs across the United States (U.S.); however, prior to 2011, it had not been proposed for Texas nursing education programs. With the inaugural drive to promote academic progression following the IOM (2011) report, "The Future of Nursing: Leading Change, Advancing Health", a goal was developed to reduce duplication of content in the Associate Degree and Baccalaureate Nurse Education Program curricula in Texas [7]. Thirteen Texas programs initially adopted CBC and, by the fall of 2016, this number increased to 17 .

For this systematic review, CBC was studied using a Strength, Weakness, Opportunity, and Threat (SWOT) analysis to determine the presence of trends that relate to nursing education. The overarching goal of this systematic review is to provide regulators and educators with evidence of the benefits and challenges of $\mathrm{CBC}$ in nursing education programs.

\section{Methods}

The literature search for nursing education concept-based curriculum was undertaken using the databases: Academic Search Complete, ProQuest Nursing, CINAHL, and PubMed. Search terms used were nursing, education, concept(s), concept-based, and nursing education. Limiters were English language and peer-reviewed academic or research publications from 1990-2017. Single abstracts, letters, and reviews of books or reports were not considered. Sixtyfour reports were retrieved, 32 reports met eligibility and are included in the qualitative synthesis of the SWOT analysis to CBC.

Abstracts were analyzed to determine applicability to CBC's development, strategies for implementation, and outcome evaluation highlighting SWOT attributes. A total of 32 reports are included in this review. Most of the reports $(n=30 ; 94 \%)$ were from the U.S., with one each from Canada and Australia. The reports described educational experiences in implementing courses in nursing undergraduate curricula. Themes were identified to create categories, such as $\mathrm{CBC}$ development, $\mathrm{CBC}$ implementation into the curriculum, and the evaluation of the implementation of $\mathrm{CBC}$ (outcomes). Eleven reports were identified as addressing $\mathrm{CBC}$ development, 10 reports discussed $\mathrm{CBC}$ implementation into the curriculum, and 11 reports dealt with the evaluation of the implementation (outcomes). Results are discussed by category.

\section{Results}

\section{Developing a Concept-based Curriculum}

The faculty impetus for considering implementation of $\mathrm{CBC}$ was a concern to reduce curricular overload, which was an overarching theme found in the majority of the eleven reports $(n=10$; 91\%). Other themes included revising the curricula to encourage students to develop new ideas or concepts based on current and past knowledge $(\mathrm{n}=9 ; 82 \%)$; allowing students to be active participants in learning $(\mathrm{n}=6 ; 55 \%)$; and integrating student-centered interactive and innovative curricular constructs in a collaborative environment, focusing on concepts $(n=10 ; 91 \%)$, rather than on content-laden courses.

Conceptual frameworks grounded in nursing clarify areas of responsibility and identify nursing's contribution to healthcare. These frameworks are dynamic, providing bases to explain, understand, and organize knowledge into "what" and "how", and are periodically reassessed and revised [16]. In programs where $C B C$ is used, intellectual development is as important as gaining new knowledge. For CBC development to occur, faculty need to be retrained and the curriculum must be redesigned to increase the level of abstraction associated with concepts that encourage organization and processing of greater amounts of factual information [2].

A plethora of possible concepts can be considered when developing $\mathrm{CBC}$. There is no standard number, nor are there right or wrong concepts. Concepts should be derived from a health continuum that incorporates wellness, health promotion, and acute and chronic illnesses based on all age groups, health, and environment. Faculty must decide which concepts represent contemporary nursing practice and which concepts will address the attributes of the nursing education program while providing clear, understandable concepts for students. Concepts are not derived from theory, but reflect trends in healthcare. A benchmark approach may be used to validate and finalize the selection of concepts when faculty develop CBC [17].

Goodman (2014) categorizes concept-based curriculum into four domains: biophysical, psychosocial, professional, and the health care system, providing various clinical and professional challenges that nurses face [18]. For instance, rather than focusing on disease processes, biophysical concepts allow patients to be managed with conditions or diseases that involve deviations in these processes. Graduates from concept-based programs are considered corecomplete, transitioning seamlessly into advanced nursing education programs, overcoming barriers associated with different entry requirements among universities and inconsistent preparation in nursing education [18]. Concepts, which are agreed upon by the entire faculty, may include: informatics, evidence-based practice, clientcentered care, leadership, management, health promotion, patient safety, interdisciplinary collaboration, and quality improvement. Each concept is introduced in the first semester, which focuses on assessment and basic nursing care.

The second semester focuses on concepts related to health promotion and chronic health issues, with acute health issues in the 
third semester and life-threatening healthcare concerns in the fourth semester. Exemplars are chosen based on NCLEX ${ }^{\oplus}$ testing blueprint and discharge diagnoses from hospitals. $\mathrm{CBC}$ progresses from simple to complex across the lifespan. Faculty identify which concepts and exemplars are taught in each course [19-20].

Active learning principles are used in developing $\mathrm{CBC}$ in nursing education as students are encouraged to be active participants in collaborative environments, as there is a relationship between teaching concepts, meaningful learning, and the ability to transfer knowledge to applicable situations. Concepts and exemplars are presented to students with explicit descriptions of how one relates to the other. By recognizing relationships and principles gained with learning concepts, generic knowledge can be transferred from didactic to clinical settings $[3,21]$.

Concepts related to professional nursing include professional attributes, nurse practice responsibilities, and core roles. To support the concepts, exemplars should be based on global, national, state, and local incidence and prevalence rates for regionally dominant population groups across the lifespan. Integration of diverse populations into practice settings encourages clinical learning activities and clinical experiences with a variety of population groups of all ages in acute care and community settings. In these settings, it is essential that clinical faculty link didactic concepts to clinical practice settings [8,22-23]. Faculty must be willing to learn how to teach using concepts, rather than focusing on content [8]. Faculty resistance is attributed to concern that a change to CBC will result in lower NCLEX scores. However, faculty have supported this curricular approach, as it prepares graduates with advanced critical thinking, applications, and information management skills, which are critical for nurses [12].

By shifting to $\mathrm{CBC}$, students are able to transfer learning to new situations. Concepts progress from simple to complex across curriculum. Exemplars are models, patterns, or cases, that enable students to apply information to scenarios. Learning is retained, retrievable and applicable, and the volume of information decreases. Faculty develop unfolding case studies that span the curriculum, using progressive evaluation tools, transparency in lesson organization, the use of comparing/contrasting activities, and concept mapping [2324].

Reports revealed that developing a CBC was found to be driven by faculty desire to reduce content overload; to boost student knowledge acquisition through active learning; and to integrate studentcentered constructs in a concept-focused learning environment. By identifying these goals, the transition to CBC was facilitated (Table 1, Supplementary File).

\section{Implementing Concept-based Curriculum}

Of the ten reports identified as transitioning to $\mathrm{CBC}$, implementation strategies and faculty commitment were addressed ( $n=9 ; 90 \%)$. Additional themes included concept selection and incorporation into the curricula ( $\mathrm{n}=7 ; 70 \%)$; the need to reduce curricular content $(\mathrm{n}=3$; $30 \%$ ); frameworks or theories upon which to base curricular changes $(n=2 ; 20 \%)$; and possible barriers that had been encountered $(n=2$; $20 \%)$.

Transitioning to concept-based is not an easy process for a variety of reasons, such as faculty who are not supportive of the change, lack of resources and time, faculty shortages, and a lack of evaluation materials regarding successful implementation of concept-based learning [25]. The benefits of this transition, though, are that faculty become less concerned with covering vast amounts of content and more willing to provide in-depth guidance. Challenges to implementing $\mathrm{CBC}$ into the curriculum include: alternative teaching strategies, empowering students, and evaluating the outcomes of the education [14]. Moving into concept-based teaching requires learning objectives that focus on understanding and applying complex phenomena for essential understanding to allow students to analyze and evaluate phenomena under varying circumstances. Implementation requires changes in how faculty work and in the delivery of the curriculum, creating a culture shift to a student-centered, concept-based, integrated, transformational approach. Courses are not organized by systems, threatening faculty's sense of value for those who have years of experience with the traditional systems model and may opt to leave rather than learn $\mathrm{CBC}$ approaches to teaching. Faculty may struggle with the new $\mathrm{CBC}$ approach, but need to be encouraged and supported during the implementation $[6,24]$.

Extensive planning is needed as faculty and administrators must commit to the change, which involves additional responsibility, work, and resources [6]. Reasons to change to $\mathrm{CBC}$ are the complexity, settings, and management challenges of patients are increasingly complicated, necessitating today's nurses to think critically and make care decisions based on evidence-based practice [26]. Key issues for faculty to consider when transitioning to $\mathrm{CBC}$ are that faculty can build on students' prior experiences and knowledge. Dailey (2016) suggests using a core faculty group to select concepts for inclusion in the CBC [6]. This faculty group can provide consistency, directions, and support during curriculum development. The faculty need to focus on prevalent healthcare issues and be less concerned with covering vast amounts of content [6].

A suggestion for implementing $\mathrm{CBC}$ into a nursing education program begins with identifying concepts to include and threading them across the curriculum to guide assessment. Concepts are selected based on the most relevant content students are expected to learn that is prevalent in clinical learning environments, which reflect trends in healthcare. Faculty development workshops are beneficial prior to implementation [11]. When planning curricular changes, a curriculum matrix should be created to crosswalk the outcomes of each course with Commission on Collegiate Nursing Education (CCNE) Essentials and Quality and Safety Education for Nurses (QSEN). Teaching strategies that promote active learning, such as unfolding case studies, concept maps, care plans, and electronic health records, encourage students to explore concepts and exemplars while engaging in critical thinking. A variety of continuing education offerings are available to support faculty during the implementation, as it may be difficult to transition from content intensive curricula to $\mathrm{CBC}$ as faculty resist change and opt to leave [23].

Faculty must prepare students for change in curriculum by discussing conceptual learning, conceptual practice, and the reasons for the change [27]. Curriculum assessment should be conducted after the first year of implementation [11].

A concept analysis diagram (CAD) focuses teaching definitions and attributes, patterns of recognition, and the role of the nurse. It creates a visual diagram applying theory to practice and concepts to patient care, encouraging higher-level thinking while reinforcing patientcentered care. There are many ways CAD may be used: to introduce the students to the concepts in the classroom, in a post conference to encourage discussion of similarities and differences between patients, 
or to prepare for clinical where students note pertinent areas for their assigned patient or as they provide patient care [28]. Nielsen (2013) developed a clinical education model for implementation with $\mathrm{CBC}$ [29]. The student learns about the concept for an assigned patient and shares this information during the debrief session with the clinical group. The group then relates the concept to a variety of patients with alternate diagnoses. This post-conference discussion facilitates learning about the concept in a variety of situations [29].

The majority of the reports identified as implementing CBC discussed strategies and the need for faculty commitment to ensure success during the change process. Frameworks and theories, upon which to base change; concept selection, which facilitates content reduction and enhances deep learning; and potential barriers, such as inexperienced faculty; were also found in the reports. After $\mathrm{CBC}$ has been implemented into the curriculum, the outcomes must be evaluated and, if necessary, revisions made (Table 2, Supplementary File).

\section{Evaluating Concept-based Curriculum}

Of the 11 reports whose theme was the evaluation of $\mathrm{CBC}$ implementation, models and tools, such as focus groups, surveys, and measures of clinical judgment, were discussed $(n=9 ; 82 \%)$. Additional assessments included the impact of $\mathrm{CBC}$ on students' critical thinking and ability to apply new knowledge across a variety of patient care scenarios ( $\mathrm{n}=6 ; 55 \%)$; faculty's knowledge or reticence to adopt CBC $(\mathrm{n}=7 ; 64 \%)$; and measurable outcomes, such as NCLEX pass rates for first-time testers, graduation rates, assessments of critical thinking, and program satisfaction $(n=8 ; 73 \%)$.

Despite interest in $\mathrm{CBC}$, there is little published data regarding student outcomes. The effectiveness of $\mathrm{CBC}$ can be evaluated by analyzing admission, progression, and graduation rates; the results of standardized tests and NCLEX first-time pass rates; and student and faculty satisfaction [27]. Gooder \& Cantwell (2017) conducted a mixed-method study of student experiences during a curriculum revision, evaluating individual survey responses and student focus groups [25]. The purpose was to determine students' perceptions of the curriculum change and effect on their learning. Students reported that participating in discussions enhanced critical thinking, improved peer relationships, and enabled the application of new knowledge, adding that redundancy and busy work were dissatisfiers. The authors found students place more emphasis on how education is organized and delivered rather than the quality of the education [25] Elliott (2017) qualitatively evaluated course competencies related to professional values of nursing students by analyzing 75 written assignments [30]. The concepts appreciation for professional values and disillusionment with unprofessional behaviors were identified, with students acknowledging a variety of professional values [30].

Nielsen (2016) reported faculty variability with knowledge of concepts led to minimal discussion with students regarding complexities of care and subtle changes in patients' conditions, resulting in a loss of ability to connect clinical experiences to didactic learning [31]. However, when faculty became less involved with monitoring student safety in providing interventions and more supportive of student learning, students were better able to understand the relationships found in patient assessments, thus enabling the transfer of learning. Faculty and student interactions increased through collaborative learning [31].
As faculty gain expertise with $\mathrm{CBC}$, courses, exemplars, and clinical courses can be modified, but major curriculum changes should not occur for at least two years. Murray, Laurent, and Gontarz (2015) developed a Curriculum Evaluation Checklist where faculty evaluated the curriculum using nine methods: multiple choice exam review, documents review, student project review, observation of students, observation of instruction, survey regarding clinical sites, survey of stakeholders, NCLEX results, and student results on a commercially available exit exam [19]. The challenge during the evaluation was the time required to complete the comprehensive initial evaluation. Faculty reported direct observation, documentation of findings, committee review and discussion, and presentation of findings in curriculum workshops were time-consuming. Faculty acknowledged ongoing, comprehensive curriculum evaluation was needed to ensure positive program outcomes. Program completion rates rose following $\mathrm{CBC}$ implementation and the results of the study suggest the curriculum change was positive [19].

In a study by Giddens and Morton (2010), faculty reported a reduction in content load, a perceived repetition of content, and improved coordination of community-based clinical experiences [32]. Faculty also reported there was a need for more pharmacology, pathophysiology, and NCLEX-RN preparation content across the lifespan. With regards to selecting concepts to include in the curricula, faculty recommended limiting the number of concepts until after the courses were taught and formative and summative evaluations were conducted. Summative evaluations included assessments of learning activities, courses, overall program achievement of goals and outcomes, retention rates, graduation rates, and NCLEX pass rates. Input was sought from faculty, students, alumni, and employers. Since a change in the curriculum may result in a decline in NCLEX pass rates, faculty reported concern about maintaining NCLEX pass rates. Students were also surveyed regarding strengths and weaknesses of curriculum, content redundancy, successful learning strategies, and challenges [32].

Duncan and Schulz (2015) compared program outcomes of a traditional, systems-based curriculum (TC) to CBC [33]. Outcomes included NCLEX pass rates for first-time testers, graduation rates, critical thinking assessments from standardized exams, and evaluations of student satisfaction. Few differences were found in program outcomes between the two types of curricula. For $\mathrm{CBC}$, the undergraduate program was shortened from five to four semesters and admissions were changed from every semester to yearly, which increased admissions and the number of graduates who enter practice. Education strategies included problem-based learning, student engagement activities, and feedback, which were attributed to strengthening student self-efficacy. A decline was reported for first time NCLEX pass rates for the first graduating class after CBC was implemented compared to students taught using TC. However, the pass rates improved with subsequent graduating classes [33].

Lewis (2014) conducted a study to measure program outcomes (NCLEX, retention, and graduation rates) with three cohorts who were pre- and post- CBC implementation [20]. The hypothesis was that $\mathrm{CBC}$ would improve retention and on-time graduation, while not negatively affecting other program outcomes. The purpose of the study was to demonstrate the effectiveness of $\mathrm{CBC}$ to enable students to understand and apply knowledge to new situations [20]. The program began with a focus on assessment and wellness in the first semester, progressing to acute and life-threatening scenarios in the final semester. Results showed that program completion rates 
improved significantly (4.0\%), while retention, graduation, employerand student-satisfaction, and NCLEX pass rates did not change. Program outcomes that had negative changes were student end-ofprogram satisfaction and alumni satisfaction, which decreased [20].

In a study by Patterson et al. (2016), faculty identified issues with the concepts that were taught [11]. Concepts that spanned the curriculum should be presented to expand on the knowledge the student has learned and not be repetitive of what was taught in a previous course. The results revealed that some faculty continued to teach using the medical model, because of a lack of understanding of the concepts and exemplars. Faculty were able to identify and correct curricular issues through the use of formative evaluations. Results of this study were that NCLEX pass rates remained stable (91\%), students were satisfied (87\%-97\% agreeing or strongly agreeing), critical thinking skills improved, and faculty were more involved with curriculum [11]

A small-sample study of subjects using concept-based learning activities was used to evaluate the development of clinical judgment. Since concept-based learning activities address the theory-practice gap, students focused on one concept each clinical day to learn various ways the concept was applied to multiple patients, thus facilitating deeper learning. Students reviewed pathophysiology and patient information before applying the concept in the clinical setting. The treatment group scored statistically high in clinical judgment. Students reported it was easier to apply learning about the concept when there were obvious deviations from the norm. The results suggest concept-based learning activities have a positive impact on clinical thinking and clinical judgment [34].

Evaluation measures of $\mathrm{CBC}$ implementation included a variety of methods and tools, such as focus groups, surveys, and measures of students' clinical judgment. Assessments of the impact of CBC on students' critical thinking and ability to apply new knowledge in the clinical setting were also measured to determine effectiveness of CBC on outcomes, such as NCLEX pass rates for first-time testers, graduation rates, assessments of critical thinking, and program satisfaction. Faculty's willingness to embrace the curricular changes and their knowledge of $\mathrm{CBC}$ curriculum were also evaluated as considerations to program success (Table 3, Supplementary File).

\section{Discussion}

A systematic review was performed to determine the state of the science of $\mathrm{CBC}$ implementation in nursing education. Of the 32 reports retrieved and determined to meet eligibility, a table of qualitative synthesis of the strengths, weaknesses, opportunities, and threats (SWOT) to CBC was created. The SWOT analysis is categorized by $\mathrm{CBC}$ development, implementation into the curriculum, and evaluation.

Strengths found for CBC development revealed that students are encouraged to problem solve, thus enhancing understanding of patient needs and nursing practice. Graduates from CBC programs are able to easily transition into the role of the professional nurse and provide safe patient care. Faculty report that teaching focuses on pertinent content, utilizing student-centered, active learning strategies where learning is retained, retrievable and applicable.Weaknesses include the need for faculty to find teaching experiences to develop students' critical thinking. In traditional clinical learning environments, students work with patients while applying new knowledge. In $\mathrm{CBC}$, faculty and facility nurses need to be retrained so that students take advantage of learning experiences rather than limiting learning occurrences to an assigned patient. Opportunities for faculty include the ability to have input into the selection of concepts and exemplars, which should be based on global, national, state, and local prevalence rates across the lifespan.Threats are that curriculum must be redesigned, moving from traditional to $\mathrm{CBC}$. Concern that a change to $\mathrm{CBC}$ will result in lower NCLEX scores was frequently reported. Potential barriers, such as inexperienced faculty, and faculty who are resistant to change, may also impact the success of $\mathrm{CBC}$ development.

The strengths of transitioning to $\mathrm{CBC}$ include faculty willingness to reduce content overload to focus on guiding students to understand, apply, analyze, and evaluate a variety of patient care situations. Weaknesses include the need for extensive planning with faculty and administrators' commitment to the new curriculum, which may necessitate additional work, and resources. Opportunities include developing active teaching strategies, enabling students, and evaluating the outcomes of the implementation of CBC. Faculty may struggle with the new curricular approach, but need encouragement and support during the transition. Threats to transitioning to $\mathrm{CBC}$ support that the change is not an easy process. For instance, faculty may not support the change, there is a lack of resources, or faculty shortages create workload issues. When courses are not organized by the traditional systems approach, faculty may feel devalued and leave rather than learn $\mathrm{CBC}$.

In evaluating the implementation of $\mathrm{CBC}$, strengths include critical thinking improved, peer relationships strengthened, and new knowledge application was facilitated. Students were able to transfer learning to connect relationships found in patient assessments. Education strategies included problem-based learning, student engagement activities, and feedback, which have a positive impact on clinical thinking and clinical judgment. A reported weakness was that concepts that spanned the curriculum should build on learning and not be repetitive of what was taught in a previous course or semester. This presents an opportunity for evaluation after $\mathrm{CBC}$ implementation with possible revisions for improvement. Evaluation measures may include surveys of current students, faculty, and alumni; critical thinking; and NCLEX pass rates. A threat may include declines for first time NCLEX pass rates for the first graduating class after CBC implementation. However, in the reports included in this systematic review where the NCLEX pass rate was discussed, it was reported that the rate improved with subsequent graduating classes. In some cases, faculty continued to teach using the medical model, because of a lack of understanding the concepts and exemplars.

\section{Conclusion}

The systematic review of $\mathrm{CBC}$ found support for the development, implementation and evaluation of $\mathrm{CBC}$. In considering transitioning to $\mathrm{CBC}$, faculty reported a desire for students to be able to apply information to new situations, analyze connections among ideas, and evaluate decisions. Most programs developed CBC by identifying concepts for inclusion, selecting exemplars, categorizing content according to themes, and mapping it across the curriculum. Some programs $(n=6 ; 60 \%)$ chose to implement the curriculum using constructivist learning theory, which allows faculty to build upon students' prior experiences and acquired knowledge from previous educational endeavors. Concept-based curricular approaches were found to promote higher levels of thinking, such as evaluating, analyzing, and processing; and to improve critical thinking and clinical judgment as students apply new knowledge within the frame of the concept, and analyze information. Faculty can become innovators and front-runners in nursing education, while reducing content overload. 
Citation: Lee SK, Willson P (2018) Concept-based Curriculum Development, Implementation, and Evaluation: A Systematic Review. Int J Nurs Clin Pract 5: 271. doi: https://doi.org/10.15344/2394-4978/2018/271

Page 6 of 6

\section{Competing Interests}

The authors declare that no competing interests exist.

\section{References}

1. Bloom's Taxonomy of Learning (2015).

2. Erickson H (2007) Concept-Based Curriculum and Instruction for the Thinking Classroom. Cheltenham, Victoria: Hawker Brownlow Education.

3. Getha-Eby T, Beery T, Xu Y, O'Brien B (2014) Meaningful learning Theoretical support for concept-based teaching. J Nurs Educ 53: 494-500.

4. Giddens J, Brady D (2007) Rescuing nursing education from conten saturation: The case for a concept-based curriculum. J Nurs Educ 46: 6569.

5. Kantor S (2010) Pedagogical change in nursing education: One instructor's experience. J Nurs Educ 49: 414-417.

6. Dailey J (2016) The concept-based curriculum: Key points for a transition MO: St. Louis Elsevier Academic Consulting Group.

7. Institute of Medicine (2011) The Future of Nursing: Leading change, advancing health. Washington, DC: The National Academies Press.

8. Giddens J, Brady D, Brown P, Wright M, Smith D, et al. (2008) A new curriculum for a new era of Nursing Education. Nurs Educ Perspect 29: 200-204

9. Sportsman S (2016a) Concept-based curricula in nursing: Perceptions of the trend. MO: St. Louis Elsevier Academic Consulting Group.

10. Hardin P, Richardson S (2012) Teaching the Concept Curricula: Theory and method. J Nurs Educ 5: 1-4.

11. Patterson L, Crager J, Farmer A, Epps C, Schuessler J (2016) A strategy to ensure faculty engagement when assessing a concept-based curriculum. J Nurs Educ 55: 467-470.

12. Giddens J, Keller T, Liesveld J (2015) Answering the call for a Bachelorsprepared nursing workforce: An innovative model for academic progression. J Prof Nurs 3: $1445-451$

13. Decker K, Hensel D, Kuhn T, Priest C (2017) Innovative implementation of social determinants of health in a new concept-based curriculum. Nurs Educ 42: 115-116.

14. Giddens J (2016) Underestimated challenges adopting the conceptua approach. J Nurs Educ 55: 187-188.

15. Heims M, Boyd S (1990) Concept-based learning activities in clinical nursing education. J Nurs Educ 29: 249-254.

16. Gold C, HaasS, King I (2000) Conceptual frameworks: Putting the nursing focus into core curricula. Nurs Educ 25: 95-98.

17. Giddens J Wright, M, Gray I (2012) Selecting concepts for a concept-based curriculum: Application of a benchmark approach. J Nurs Educ 51: 511 515.

18. Goodman $T$ (2014) Nursing education moves to a concept-based curriculum. AORN Connections 99: C7-C8.

19. Murray S, Laurent K, Gontarz J (2015) Evaluation of a concept-based curriculum: A tool and process. Teaching and Learning in Nursing 10: 169175.

20. Lewis L (2014) Outcomes of a concept-based curriculum. Teaching and Learning in Nursing 9: 75-79.

21. Brandon A, All A (2010) Constructivism theory analysis and application to curricula. Nurs Educ Persp 31: 89-92.

22. Forbes $M$, Hickey $M$ (2009) Curriculum reform in baccalaureate nursing education: Review of the literature. Inter J Nurs Educ Scholarsh 6: Article27.

23. Lee S, Lockhart L, Sanders E (2015) A case for concept-based nursing education. Texas Nursing Voice 9: 3-5.

24. Hendricks S, Wangerin V (2017) Concept-Based Curriculum: Changing attitudes and overcoming barriers. Nurs Educ 42: 138-142.

25. Gooder V, CantwellS (2017) Student experiences with a newly developed concept-based curriculum. Teaching and Learning in Nursing 12: 142-147.
26. Deane W, Asselin M (2015) Transitioning to Concept-Based Teaching: A discussion of strategies and the use of Bridges Change model. J Nurs Educ Prac 5: 52-59.

27. Sportsman S (2016b) Strategies for encouraging the acceptance and successful implementation of a concept-based curriculum. MO: St. Louis Elsevier Academic Consulting Group.

28. Higgins B, Reid H (2017) Enhancing "conceptual teaching/learning" in a concept-based curriculum. Teaching and Learning in Nursing 12: 95-102.

29. Nielsen A, Noone J, Voss H, Mathews $L$ (2013) Preparing nursing students for the future: An innovative approach to clinical education. Nurs Educ Prac 13: $301-309$

30. Elliott A (2017) Professional values competency evaluation for students enrolled in a concept-based curriculum. J Nurs Educ 56: 12-21.

31. Nielsen A (2016) Concept-Based Learning in Clinical Experiences: Bringing Theory to Clinical Education for Deep Learning. J Nurs Educ 55: 365-371.

32. Giddens J, Morton N (2010) Report card: An evaluation of a concept-based curriculum. Nurs Educ Perspect 31: 372-377.

33. Duncan K, Schulz P (2015) Impact of change to a concept-based Baccalaureate Nursing curriculum on student and program outcomes. J Nurs Educ 54: S16-S20.

34. Lasater K, Nielsen A (2009) The influence of concept-based learning activities on students' clinical judgment development. J Nurs Educ 48: 441446.

35. Giddens J (2009) Changing paradigms and challenging assumptions: Redefining quality and NCLEX-RN® pass rates. J Nurs Educ 48: 123-124. 